\title{
STATUS OF X-BAND PULSED MAGNICON PROJECT*
}

\author{
O.A. Nezhevenko, V.P. Yakovlev, J.L. Hirshfield, Omega-P Inc., New Haven, CT 06511, USA. \\ S.H. Gold, and A.W. Fliflet, Beam Physics Branch, Plasma Physics Division, Naval Research \\ Laboratory, Washington, DC 20375, USA. \\ A.K. Kinkead, LET Corp., Washington, DC 20007, USA.
}

\begin{abstract}
A frequency-doubling magnicon amplifier at $11.4 \mathrm{GHz}$ has been designed and built as the prototype of an alternative microwave source for the Next Linear Collider project, and to test high power active rf pulse compressors, RF accelerating structures, etc. The tube is designed to produce $\sim 60 \mathrm{MW}$ at $60 \%$ efficiency and 59 $\mathrm{dB}$ gain, using a $470 \mathrm{kV}, 220 \mathrm{~A}, 2 \mathrm{~mm}$-diameter beam. The results of beam envelope measurements and the first observations of RF performance are presented.
\end{abstract}

\section{INTRODUCTION}

The magnicon, an RF source based on circular deflection of an electron beam, is an attractive alternative to the klystron for accelerator applications [1]. A magnicon has already demonstrated experimentally an output power of $55 \mathrm{MW}$ and efficiency of $56 \%$ in a 1 $\mu$ sec pulses at $7 \mathrm{GHz}$ [2]. An $11.4 \mathrm{GHz}$ magnicon [3,4] is being developed jointly by Omega-P and NRL as a potential high efficiency RF source for the NLC and as the basis of a facility for testing novel components and approaches for a future linear collider. A schematic layout of this magnicon is shown in Fig. 1. The tube consists of an electron gun, $\sim 6.5 \mathrm{kG}$ solenoid, RF circuit and collector insulated from ground. The $500 \mathrm{kV}$ diode gun is designed to produce a beam area compression of 2500:1 and a beam diameter in the magnet of about 1.5 $\mathrm{mm}$ [5]. The complete RF circuit has six $5.712 \mathrm{GHz}$ $\mathrm{TM}_{110}$ deflection cavities (a drive cavity, three gain cavities and two penultimate cavities), followed by an $11.424 \mathrm{GHz} \mathrm{TM}_{210}$ output cavity. In contrast to [2] the two penultimate cavities are not coupled and operate in the angle summing mode in order to eliminate an instability that limits the pulse width [6]. To extract RF power there are two output apertures at the downstream end of the output cavity, separated by $135^{\circ}$, and ending in WR-90 waveguide. The tube does not have output windows and WR-90 waveguides are connected to SLACtype vacuum loads directly. The gun is supplied with a gate valve [7] in order to protect the cathode while changing experimental setups.

In initial design, the beam optics and RF system were optimized for a beam perveance of $0.59 \times 10^{-6} \mathrm{~A}-\mathrm{V}^{-3 / 2}$. However, an underestimation of thermal expansion and misalignments made during the gun manufacturing led to an excessive current corresponding to a perveance of

*Work supported by DoE and ONR
$0.68 \times 10^{-6} \mathrm{~A}-\mathrm{V}^{-3 / 2}$. This is expected to result in diminution in efficiency down to $57-58 \%$ rather that the $63-65 \%$ that was anticipated for a properly constructed gun.

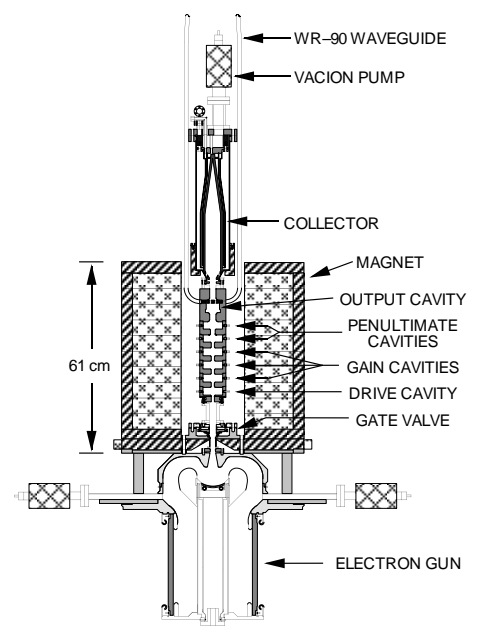

Figure 1. The magnicon schematic.

Table 1 summarizes differences in predicted performance for the magnicon with the gun as now built, and as originally designed based on detailed simulation studies.

Table 1. Parameters of the X-band magnicon.

\begin{tabular}{|l|l|l|}
\hline & $\begin{array}{l}\text { Initial } \\
\text { design }\end{array}$ & $\begin{array}{l}\text { Realistic } \\
\text { value }\end{array}$ \\
\hline Frequency, GHz & 11.424 & 11.424 \\
\hline Power, $\mathrm{MW}$ & 65 & 60 \\
\hline Efficiency, \% & 65 & 58 \\
\hline Pulse duration, $\mu$ sec & 1 & 1 \\
\hline Maximal repetition rate, $\mathrm{Hz}$ & 10 & 10 \\
\hline Gain, $\mathrm{dB}$ & 62 & 59 \\
\hline Drive frequency, GHz & 5.712 & 5.712 \\
\hline Beam voltage, $\mathrm{kV}$ & 500 & 470 \\
\hline Beam current, $\mathrm{A}$ & 210 & 220 \\
\hline Perveance, $\mathrm{A}-\mathrm{V}^{-3 / 2} \times 10^{-6}$ & 0.59 & 0.68 \\
\hline Beam diameter in magnet, $\mathrm{mm}$ & 1.5 & 2 \\
\hline
\end{tabular}

\section{BEAM MEASUREMENTS}

After an accident at the end of 1999, the gun was repaired by Calabazas Creek Research, and tested up to a beam power of $100 \mathrm{MW}$. The resulting beam perveance 
is $0.68 \times 10^{-6} \mathrm{~A}-\mathrm{V}^{-3 / 2}$ (instead of $0.64 \times 10^{-6} \mathrm{~A}-\mathrm{V}^{-3 / 2}$ as in the first experiments [4]) on account of an erroneous assumption for thermal expansion, resulting in a reduced hot anode-cathode gap. This leads to beam mismatching with the magnet system, and does not yield full advantage from magnet system corrections introduced earlier [4].

In order to characterize and optimize the electron beam, a high-vacuum bakable beam analyzer was designed and built [8]. A schematic of the analyzer is shown in Fig. 2. The location of the beam edges is determined by using a set of $8 \mathrm{~mm}$-wide graphite apertures (Fig. 2) that are translated laterally until they just begin to collect current from the edge of the beam.

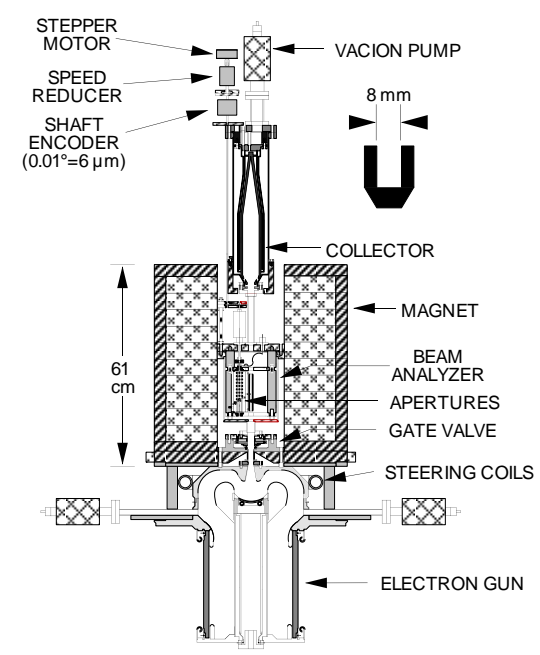

Fig. 2 Beam analyzer.

The measured beam envelope containing $95 \%$ of the beam current for the optimal case is shown in Fig. 3. The simulated beam envelope containing the same portion of current is shown also. One can see that amplitude and

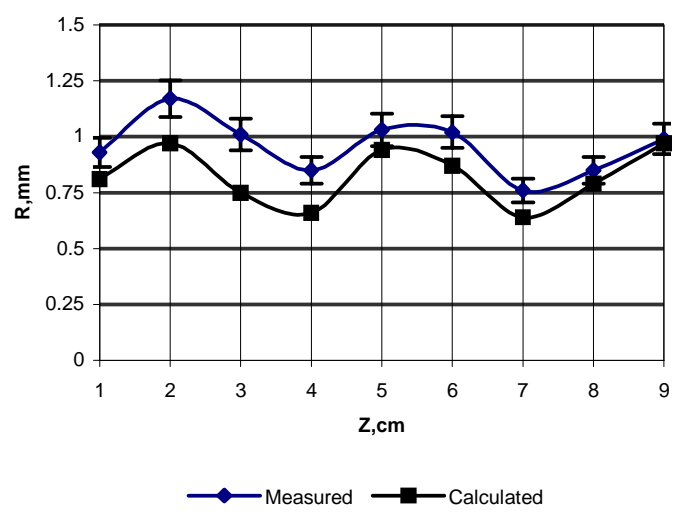

Figure 3. The beam envelope containing $95 \%$ of the beam current.

phase of the beam scalloping are in excellent agreement with the simulation result, which indicate that the beam is axially symmetric, but the maximum beam diameter exceeds the calculated value by $15-20 \%$. One of the possible reasons for this discrepancy is that in this design the cathode and focus electrode are mounted on separate stems [5] and have different thermal expansion, which is not known with precision. Consequently, some uncertainty in the gun geometry exists even once the true perveance is measured. However, the electron optics can - in principle - be corrected in account for the true perveance, and the beam diameter can be reduced to $\sim 1.7$ $\mathrm{mm}$. This would be achieved by correcting the shape of the focus electrode and increasing the distance between the gun and magnet system.

\section{FIRST RESULTS OF RF TESTS}

During the initial high-power conditioning campaign for the tube (Nov. 2000-Feb. 2001), the magnicon output power reached about $25 \mathrm{MW}$ in $0.2 \mu \mathrm{sec}$ pulses and about $15 \mathrm{MW}$ in $1.2 \mu \mathrm{sec}$ pulses. An example of experimental traces obtained during the conditioning is shown in Fig. 4. Output power calibration was carried out by calorimetric measurements of average RF power in the loads.

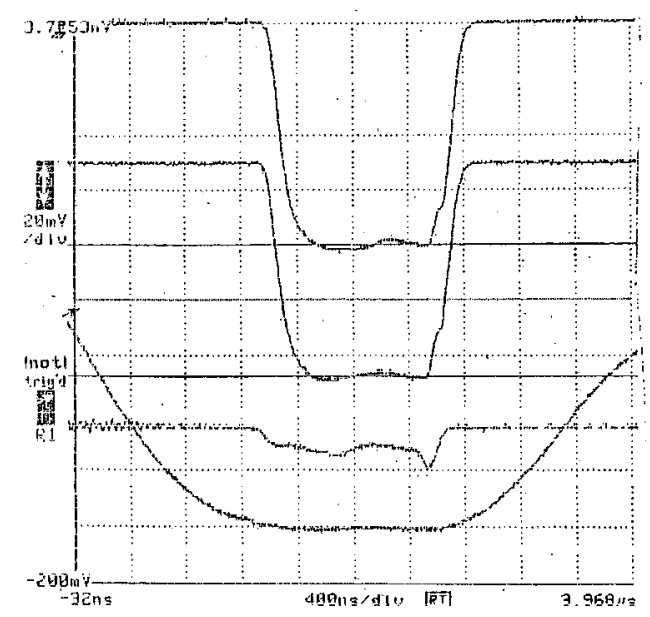

Fig. 4. Example of experimental traces for partiallyconditioned X-band magnicon using a $1.2 \mu$ sec RF drive pulse, with measured output of $7.8 \mathrm{MW}$ from the left output waveguide (top trace) and 7.2 MW from the right output waveguide ( $2^{\text {nd }}$ trace), for a total output of $15 \mathrm{MW}$. Third trace is diagnostic signal from cavity \#4. Bottom trace is modulator voltage. With a $0.44(0.22) \mu \mathrm{sec} R F$ drive pulse, a total output power of 20 (25) MW was measured.

As in the case of the $7 \mathrm{GHz}$ magnicon [2], conditioning this tube has proven to be a protracted process due to poor vacuum conditions, low repetition rate and single-shift 5day operation, but no unexpected events occurred. Power is still limited by multipactoring, exhibiting by characteristic distortion in the pulse shape and substantial worsening in vacuum. The repetition rate is typically restricted to $1-2 \mathrm{~Hz}$, on account of vacuum limitations. 
An example of the dependence of output power upon input power is shown in Fig. 5. One can see that, in this regime, the tube essentially operates as a linear amplifier. The output signal was analyzed with a shorted, slotted line and no parasitic oscillations were found.

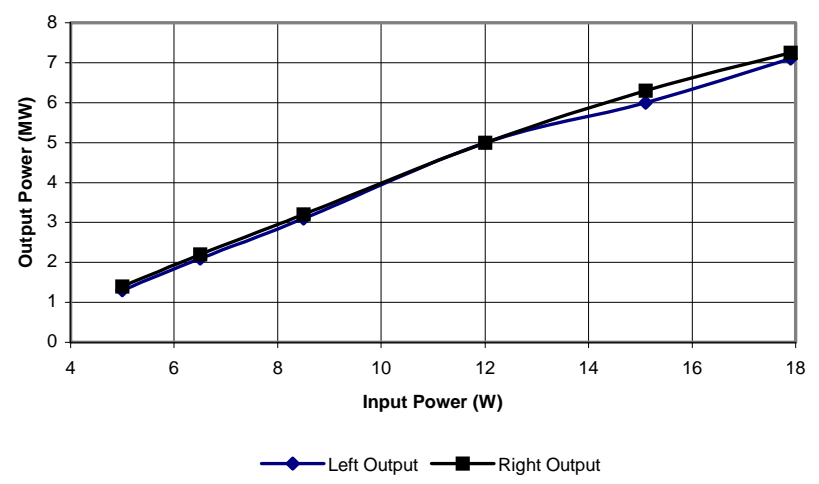

Figure 5. The measured drive curve.

The measured and calculated bandwidth are shown in Fig. 6. One can see that measured bandwidth is wider than the calculated one. Previous experiments with magnicons indicate that our simulations of the bandwidth are reliable (see e.g. [2]). The most probable cause of this discrepancy is electron loading in incompletely conditioned magnicon cavities. An additional confirmation of this is that the measured gain is lower than calculated.

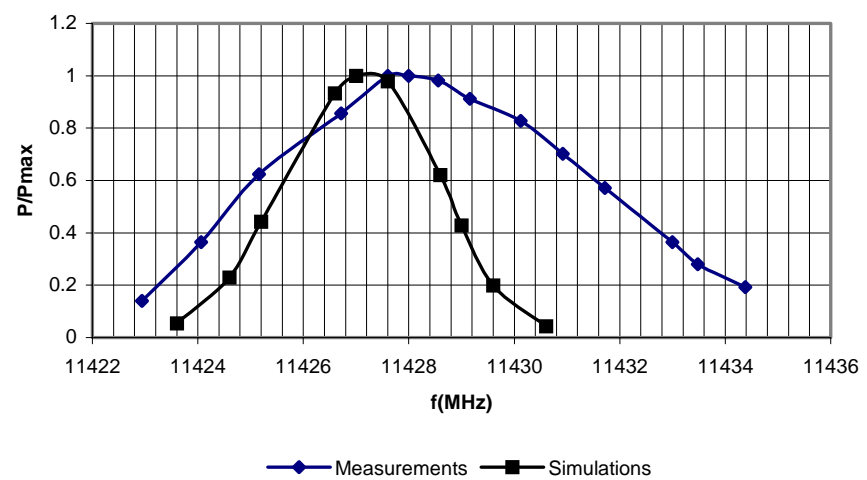

Figure 6. The measured and calculated magnicon bandwidth.

In addition to tests when the tube was terminated into matched loads, it was also tested with a resonance load, namely an active RF pulse compressor [9]. One of the two magnicon outputs was connected to the compressor, effectively a narrow-band high-Q resonator. During these tests [10] no evidence was found of instabilities in the magnicon.

\section{CONCLUSIONS}

The magnicon gun has been tested up to its design power of $100 \mathrm{MW}$ and the beam envelope was measured, showing a beam diameter of $\sim 2 \mathrm{~mm}$. This result allows one to anticipate an output power of $\sim 60 \mathrm{MW}$ and an efficiency of $\sim 58 \%$. During the initial conditioning campaign, RF output power of $25 \mathrm{MW}$ in $0.2 \mu \mathrm{sec}$ pulses and about $15 \mathrm{MW}$ in $1.2 \mu \mathrm{sec}$ pulses was achieved. The initial conditioning campaign was suspended at the end of February, 2001 to allow preliminary tests of the Omega-P active rf pulse compressor. These experiments confirmed, as predicted, that the magnicon can operate directly with resonant loads, such as high-Q cavities and/or accelerating structures.

Conditioning is being resumed in June 2001. Expectations remain strong that the design output power of $60 \mathrm{MW}$ will be achieved after full conditioning, since no evidence to suggest the contrary emerged during the initial period of conditioning.

Operation of the Omega-P/NRL magnicon is now establishing the research facility at NRL as only the second laboratory in the USA, after SLAC, where highpower microwave development at the NLC X-band frequency can take place.

Near-term plans include continuation of the tube conditioning, tests of different versions of RF pulse compressors, and high gradient tests of a dielectric loaded accelerating structures [11] in a collaboration with ANL.

\section{REFERENCES}

[1] O.A. Nezhevenko, Phys. Plasmas, 7, p. 2224, May 2000.

[2] E.V. Kozyrev et al., EPAC98, Stockholm 1998, p.1897.

[3] S.H. Gold et al., Phys. Plasmas, 4, p. 1900, 1997.

[4] O.A. Nezhevenko et al., PAC99, New York 1999, p.1049.

[5] V.P. Yakovlev, O.A. Nezhevenko, and R.B. True, PAC97, Vancouver 1997, p. 3186.

[6] O.A. Nezhevenko and V.P. Yakovlev, IEEE

Trans. Plasma Sci., 28, p. 542, 2000.

[7] S.H. Gold, A.K. Kinkead, and O.A. Nezhevenko, Rev. Sci. Instrum., 70, p. 3770, Sept., 1999.

[8] S.H. Gold et al., IEEE Trans. Plasma Sci., 28, p. 665, 2000.

[9] A.L. Vikharev et al., AIP Conf. Proc. 472, p. 975 (AIP, Woodbury, 1999).

[10] A.L. Vikharev et al., unpublished.

[11] S.H. Gold, and Wei Gai, "High-Power Testing of an 11.4-GHz Dielectric-Loaded Accelerating Structure," present Conference. 